Emergency Medicine

\title{
The management of acute severe asthma
}

\author{
M.E. Tatham and A.R. Gellert \\ The London Chest Hospital, Bethnal Green, London E2 9JX, UK.
}

\section{Introduction}

A recent long-term prospective study has shown that the actual mortality of asthmatics outweighs the expected mortality, particularly in young subjects (Alderson \& Loy, 1977). The standardized death rate from asthma in the 5-34 y age group has remained remarkably constant over the past century apart from a brief epidemic of deaths in the 1960s (Speizer et al., 1968). Clark (1983) states that when the standardized mortality rate for asthma is examined over a long enough period it quickly becomes apparent that the advent of new treatment has had no consistent effect.

The term acute severe asthma (Clark, 1983) has largely replaced status asthmaticus in describing attacks of increasing severity unrelieved by increased treatment. Given the depressingly constant mortality statistics and the controversy over guidelines for the assessment and management of acute severe asthma we considered a detailed review of current opinion to be of value.

\section{Pathology}

In the majority of cases of asthma deaths necropsy reveals that the lungs are bulky and tense and do not deflate when the thoracic cage is opened. The large and small bronchi stand proud of the cut surface of the lungs due to hypertrophy of their muscle walls and plugging with tenacious mucus. Rarely, in patients dying suddenly in a severe asthmatic attack, the lungs appear macroscopically and microscopically normal. Death here may well be due to overwhelming bronchoconstriction.

A third group are recognized who die in the course of a moderate asthmatic attack; they have only minor changes of cellular infiltration and mucous plugging of their airways. It has been postulated that these patients had been suffering from chronic bronchial constric-

Correspondence: A.R. Gellert M.B., M.R.C.P. (UK) Accepted: 28 December 1984 tion of gradual onset to which they had adapted but in whom a relatively minor deterioration was sufficient to cause death (Lopez-Vidriero \& Reid, 1983).

\section{Mediators}

Whatever the initiating mechanism of the asthmatic response, the resultant effect is probably the release of chemical mediators from mast cells, eosinophils, neutrophils and platelets, though it cannot be ruled out that neurogenic reflexes may sometimes stimulate bronchoconstriction directly. Primary mediators directly cause bronchial smooth muscle contraction, increase vascular permeability, increase mucous gland secretion and probably affect mucociliary clearance. They also cause the release of secondary mediators such as prostaglandins and vasoactive amines. Mediator release may be affected by the autonomic nervous system. Release is enhanced by a reduction in intracellular cyclic AMP levels or an increase in intracellular cyclic GMP levels. Beta sympathetic activity increases cyclic AMP levels while cholinergic mechanisms stimulate the production of cyclic GMP. It is increasingly recognized that major mediators of asthmatic reactions include histamine, leukotrienes (SRS-A), eosinophil chemotactic factor, neutrophil chemotactic factor and platelet activating factor; secondary mediators include prostaglandins and vasoactive amines (Rudd \& Wedzicha, 1982). A greater understanding of these cellular processes should allow a more rational appreciation of the pharmacological basis of treatment in asthma.

\section{Asthma deaths}

Numerous retrospective surveys of asthma mortality have shown that up to $80 \%$ of deaths were 'sudden and unexpected' (Speizer et al., 1968; Heaf, 1970; Fraser et al., 1971). Many occurred outside hospital (Cochrane 
\& Clark, 1975, Wilson et al., 1981). The time from onset of symptoms to death, when known, ranged from less than $30 \mathrm{~min}$ to $12 \mathrm{~d}$ (Ormerod \& Stableforth, 1980).

Deaths tended to occur in chronic asthmatics and were often preceded by a period of poor control. Many had had previous admissions for asthma and had suffered repeated acute attacks at home (British Thoracic Association, 1982). Patients particularly at risk were those recently discharged from hospital after a previous attack (MacDonald et al., 1976), those with marked diurnal variation in peak flow, those with markedly labile asthma (the 'brittle asthmatic') and those with gradually deteriorating airflow obstruction (Westerman et al., 1979). Many deaths were potentially avoidable. All surveys noted the frequent failure of the patient or relatives to recognize the severity of the attack. Doctors, when called, rarely used objective measures of severity and tended to undertreat (British Thoracic Association, 1982; Ormerod \& Stableforth, 1980; Fraser et al., 1971; MacDonald et al., 1976).

Evidence from records of those asthmatics who died in hospital points to inadequate assessment and little relationship between the severity of the attack and the treatment given (Cochrane \& Clark, 1975; Ormerod \& Stableforth, 1980). Underassessment of an asthmatic attack may result not only in undertreatment but in inappropriate placement of the patient within the hospital. Hetzel et al. (1977) noted that the majority of respiratory crises in asthmatics occurred on general wards. Jones (1971) demonstrated that mortality was reduced if patients were treated in an intensive care area by a team trained in the management of severe asthma.

The epidemic of asthma deaths in the 1960s was initially attributed to overuse of inhaled non-selective beta-agonists which were freely available without prescription. Indeed the mortality curve for asthma closely resembled the curve for sale of aerosols (Speizer et al., 1968; Heaf, 1970; Stolley \& Schinnar, 1978). Clark (1983) suggests that increased bronchodilator consumption, when associated with increased asthma fatalities, is more likely to indicate an excessive dependence on bronchodilators by patients and clinicians at times when asthma control is failing. Numerous other recent studies have suggested an association between asthma deaths and underuse of corticosteroids (Cochrane \& Clark, 1975; MacDonald et al., 1976; Ormerod \& Stableforth, 1980; Grant, 1982). Similar conclusions regarding an undue reliance on bronchodilators, in this case theophyllines, and an underuse of corticosteroids have been reached by Wilson et al. (1981), and Jackson et al. (1982), after investigating the recent epidemic of asthma deaths in New Zealand. Excessive use of bronchodilators is a signal that asthma control is inadequate and that further treatment is required (Clark, 1983).

\section{Clinical assessment}

Anybody should be able to recognize the gravity of the situation if an asthmatic arrives in casualty cyanosed, limp and with an altered level of consciousness. However it may be difficult to recognize those asthmatics in serious danger who present in a less dramatic fashion. In the following section we have attempted to identify those clinical features and simple investigations which may suggest that an attack is more severe than was originally suspected.

\section{History}

The speed of onset of an attack may be rapid but that in itself is not an indication of severity (Arnold et al., 1982). Reference has already been made to the risks associated with recent hospital admission for an acute attack, labile or 'brittle' asthma, excessive diurnal variation in airway calibre, and gradually deteriorating respiratory function. Jones (1971) proposed a method of grading severity based on function (Table I). He recommended that all patients with severe (grade 3) or moderate (grade 2) asthma of more than $8 \mathrm{~h}$ duration should be monitored in a high dependency area rather than a general ward.

\section{Physical examination}

The degree of breathlessness may not be a reliable guide to the severity of the attack and physical examination of the chest may not always be helpful: indeed, the danger of the 'silent chest' is well known (Stark, 1972; Clark, 1983). The use of accessory muscles, in particular the sternocleidomastoid (McFadden et al., 1973) and abdominal muscles has been shown to indicate increasing respiratory distress. Tachycardia is almost invariable and a rate of over $130 / \mathrm{min}$ is frequently associated with severe hypoxaemia (Stark, 1972; Hetzel et al., 1977). Cooke et al. (1979) found that severe tachycardia was more common in the young and most patients whose rates exceeded $150 / \mathrm{min}$ had had symptoms for less than $24 \mathrm{~h}$. However, Arnold et al. (1982) were unable to correlate tachycardia reliably with severity. Pulsus paradoxus was found by Stark (1972), Hetzel et al. (1977), and Rebuck \& Read (1971) to be a valuable indicator of severity. In the latter study, pulsus paradoxus ranging from 10 to $100 \mathrm{mmHg}$ was never present when the forced expiratory volume in one second $\left(\mathrm{FEV}_{1}\right)$ was over $40 \%$ but was invariably present when the $\mathrm{FEV}_{1}$ was less than $20 \%$ of the patient's best. On the other hand, Arnold et al. (1982) found that when pulsus paradoxus was measured, it correlated poorly with other measures of severity. 


\section{Simple investigations}

Acute electrocardiogram (ECG) changes other than sinus tachycardia are not uncommon, even in young patients or those with no co-existing heart disease. They include right axis deviation, clockwise rotation of the heart, evidence of right ventricular hypertrophy, $P$ pulmonale and ST segment or T wave abnormalities. They are not a contraindication to beta-agonist therapy and many changes resolve within hours of treatment (Rebuck \& Read, 1971; Stark, 1972; Siegler, 1977; Webb et al., 1979).

Tests of ventilatory function are essential. A low peak expiratory flow rate (PEFR) is an important sign of airway obstruction. While there is a general correlation between severity of attack and reduction in PEFR or $\mathrm{FEV}_{1}$, this is not invariable (Rebuck \& Read, 1971; Stark, 1972; Hetzel et al., 1977; Arnold et al., 1982). Both the PEFR and the FEV 1 are predominantly tests of large airway function and may not reflect significant peripheral bronchoconstriction. If the patient cannot reach $60 \mathrm{l} / \mathrm{min}$, the lowest reading on the adult meter, a paediatric meter should be used which can record rates down to zero (Rudd \& Wedzicha, 1982). The inability of an asthmatic to record a reading is often of itself indicative of an extremely severe attack (Webb et al., 1979).

It is important to monitor blood gases. Hypoxia is invariably present but there is a wide range of $\mathrm{PaO}_{2}$ values which may prevail with a given $\mathrm{FEV}_{1}$. Levels of the order of $8 \mathrm{kPa}(60 \mathrm{mmHg})$ are common. It must be remembered that hypoxia frequently persists for many days even after the disappearance of other symptoms and signs (Rebuck \& Read, 1971; Cochrane, 1983). Hypocapnia is common and any elevation of $\mathrm{PaCO}_{2}$ indicates that ventilation is proving inadequate and more rigorous treatment is required (Menitove \& Goldring, 1983). Mild respiratory alkalosis is also common in the early stages, but respiratory and metabolic acidoses may supervene as the attack worsens. A chest X-ray frequently shows hyperinflation and may be the only means of detecting a pneumothorax or pneumomediastinum.

Table I The Jones Index*

Grade 1 Able to carry out housework, or job, with difficulty

Grade 2A Confined to a chair or bed, but able to get up with moderate difficulty

Grade 2B Confined to a chair or bed, but able to get up with great difficulty

Grade 3 Totally confined to a chair or bed

Grade 4 Moribund

\footnotetext{
* Jones (1971)
}

Electrolyte imbalance, particularly hypokalaemia, is not uncommon especially in the severe attack. It has been suggested that this is due to high levels of circulating catecholamines, and the renal tubular response to stress (Webb et al., 1979; Menitove \& Goldring, 1983). In the presence of an acidosis a normal or low-normal serum potassium may in fact be masking significant intracellular potassium depletion.

No single factor has been shown to be a reliable gauge of severity. The most effective means of assessing an asthmatic attack involves the use of as many objective measures as possible but most also include a subjective clinical assessment, such as that provided by the Jones index (Table I), based on the function of the patient (Arnold et al., 1982).

\section{Treatment}

\section{Beta-agonists}

Beta-agonists are the most commonly used bronchodilators. They are believed to raise cyclic AMP levels in bronchial smooth muscle by stimulation of adenyl cyclase (Svedmyr, 1977). Salbutamol produces bronchodilation within $5 \mathrm{~min}$ of inhalation. Peak values are reached after $15 \mathrm{~min}$ and effects last up to $6 \mathrm{~h}$. There appears to be little difference between salbutamol, terbutaline and fenoterol in this respect (Tattersfield, 1983). Hetzel \& Clark (1976) showed that inhaled salbutamol had a more potent and prolonged bronchodilator effect than an equivalent intravenous dose in chronic stable asthmatics. Rossing et al. (1980) and Williams et al. (1981) found that the bronchodilator effect of beta-agonists is independent of the route of administration in acute severe asthma. Intravenous salbutamol carries with it an increased risk of side effects, such as tachycardia, tremor and hypokalaemia (Nogrady et al., 1977). In diabetics intravenous salbutamol can produce deterioration in diabetic control and may precipitate ketoacidosis (Leslie \& Coats, 1977). Patients with acute severe asthma are at risk of dysrhythmias from hypoxia, hypokalaemia and circulating catecholamine activity, and this may theoretically be aggravated by betaagonist therapy; electrocardiographic monitoring should be undertaken for all severely ill asthmatics, particularly if intravenous beta-agonists are used.

Inhalation is the preferred route of administration as fewer side effects are seen than with oral or parenteral administration (Tattersfield, 1983). Intravenous salbutamol should be reserved for those few patients who cannot use or fail to respond to nebulized salbutamol and serum potassium should be monitored and corrected (Nogrady et al., 1977). 


\section{Ipratropium bromide}

Ipratropium is a quaternary salt derivative of atropine. Its maximal effect is reached $60-90 \mathrm{~min}$ post inhalation (Tattersfield, 1983). Ward et al. (1981) found that nebulised ipratropium was as effective as nebulized salbutamol in acute severe asthma and subsequently demonstrated an additive effect with salbutamol (Ward et al., 1982). In severe asthma ipratropium may be a useful addition to the physicians's armamentarium but it may produce dryness of the mouth, throat and airways and therefore reduce expectoration of intra-bronchial plugs and mucus.

\section{Oxygen}

Humidified oxygen should be administered. Any fears of inducing carbon dioxide retention have little foundation in the setting of severe acute asthma but very high concentrations of oxygen $(>50 \%)$ may lead to oxygen toxicity and attendant pulmonary epithelial damage and pneumonitis (Cochrane, 1983). The potential risk of exacerbation of hypoxaemia by betaagonists, probably by increasing ventilation perfusion mismatching (Tai \& Read, 1967; Cochrane, 1983), underlines the need for oxygen both as a primary measure and as the preferred driving gas for nebulisers dispensing these drugs.

\section{Corticosteroids}

The precise modes of action of steroids are incompletely understood. Glucocorticoids can affect every stage of inflammatory and immunological reactivity. In low concentrations, they influence the movement and distribution of lymphocytes, neutrophils and eosinophils and decrease the concentration of these cells at inflammatory sites. They also inhibit leakage of fluid from capillary beds (Svedmyr, 1982). Many actions of corticosteroids may be explained by their ability to stimulate the synthesis of the proteins, lipomodulin and macrocortin, which inhibit phospholipase A2, thus preventing formation of the arachidonic acid metabolites leukotrienes, prostaglandins and thromboxanes (Kay, 1983). The clinical significance of this effect has not yet been assessed as most of these effects have been shown in in vitro studies with fairly high concentrations of steroids (Svedmyr, 1982).

Studies of the use of corticosteroids in acute severe asthma have produced contradictory results. Pierson et al. (1974) found a significant improvement in arterial hypoxaemia at $24 \mathrm{~h}$ independent of any improvement in ventilatory function. Luksza $(1982 \mathrm{a}, \mathrm{b})$ suggests that hydrocortisone has no role to play in severe asthma. In spite of this controversy, no convinc- ing evidence has ever been produced to show that steroids should be withheld. In the acute situation they are safe and may be life-saving (Grant, 1982). Britten et al. (1976) suggested that there is no benefit in using massive doses of corticosteroids. Maximum 11 hydroxycorticosteroid levels occur $1 \mathrm{~h}$ after an intravenous injection (Collins et al., 1970) and a recommended regimen is to give $200 \mathrm{mg}$ of intravenous hydrocortisone as a bolus followed by $4 \mathrm{mg} / \mathrm{kg}$ every $6 \mathrm{~h}$ (Collins et al., 1970; Cochrane, 1983).

\section{Theophyllines}

Aminophylline was originally thought to act by increasing cyclic AMP levels in smooth muscle through inhibition of phophodiesterase. However, it has subsequently been shown that phosphodiesterase is not significantly inhibited at tissue concentrations achieved with usual therapeutic doses. Alternative mechanisms have been proposed including alterations in smooth muscle calcium ion concentration. In addition, theophyllines are known to inhibit the effects of prostaglandins on smooth muscle and the release of histamine and leukotrienes from mast cells (Isles $\mathrm{et} \mathrm{al.,}$ 1982).

There is considerable controversy regarding the use of aminophylline as a bronchodilator in addition to beta-agonists and ipratropium in the acute situation (Josephson et al., 1979; Rossing et al., 1980; Handslip et al., 1981; Ward et al., 1982). In addition, it is a drug which may be difficult to handle. It has a narrow therapeutic margin (blood levels of $10-20 \mathrm{mg} / \mathrm{l}$ ) and serious toxic effects have been seen with levels as low as $25 \mathrm{mg} / 1$ (Zwillich et al., 1975). The half-life varies widely both within an individual and between individuals (Piafsky \& Ogilvie, 1975; Van Dellen, 1979; Conway et al., 1984). Clearance may be reduced by intercurrent viral infections (Chang et al., 1978), congestive cardiac failure, liver disease, severe airway obstruction, pneumonia and concurrent use of erythromycin, cimetidine, coumarin anticoagulants and benzodiazepines which are metabolized by the cytochrome P450 enzyme system (Nicholson \& Chick, 1973; Reitberg et al., 1981). Powell et al. (1978) showed that the reduced clearance effects of two or more of the above factors were multiplicative rather than additive. The original dosage regimen recommended by Mitenko \& Ogilvie (1973) was shown by subsequent workers to result in serum levels dangerously near or within the toxic range. This is a particular risk with intravenous bolus administration to patients already receiving maintenance oral or rectal aminophylline (Stewart et al., 1984). Woodcock et al. (1983) stressed the danger of casual administration of intravenous bolus doses of aminophylline in casualty departments and general practice. It is particularly salutory to note that the potentially lethal side effects of cardiac arrest 
and grand mal seizures are not necessarily heralded by adverse effects (Zwillich et al., 1975; Woodcock et al., 1983).

If aminophylline is to be used in patients who remain unresponsive to other forms of therapy, blood must be drawn prior to and throughout treatment to monitor theophylline levels closely. A loading dose should not be given to patients already receiving outpatient therapy (Thompson \& Hay, 1982). Powell et al. (1978) recommend the following regimen: a loading dose of $6 \mathrm{mg} / \mathrm{kg}$ (if given), followed by a maintenance infusion of $0.2 \mathrm{mg} / \mathrm{h} / \mathrm{kg}$ in the presence of congestive cardiac failure or pneumonia, $0.4 \mathrm{mg} / \mathrm{h} / \mathrm{kg}$ in the presence of severe airway obstruction, and, if none of these complications prevail, a dose of $0.5 \mathrm{mg} / \mathrm{h} / \mathrm{kg}$. This is the equivalent of $180 \mathrm{mg}$ of aminophylline 6 hourly in a $60 \mathrm{~kg}$ otherwise healthy adult (Editorial, 1980). Should theophylline levels be unavailable, no patient should receive more than one gram of aminophylline in 24 hours.

\section{General measures}

Parenteral fluids may be vital to preserve an adequate circulating volume, both because of dehydration and also high intrapulmonary pressures. Antibiotics should be given if there is evidence of infection but not routinely (Graham et al., 1982).

While it should be unnecessary to warn against the sedation of an asthmatic, a depressing number of studies note the association between sedation given to patients with severe asthma and subsequent deterioration requiring mechanical ventilation or with death (Cochrane \& Clark, 1975; Scoggin et al., 1977; Webb et al., 1979; Westerman et al., 1979). It is a wise precept to treat the asthma rather than the patient's agitation.

\section{Artificial ventilation}

A small number of patients do not improve despite the maximal therapy outlined above and further deterioration may require artificial ventilation. There is no absolute criterion for artificial ventilation; each patient must be assessed individually but any one or any combination of factors suggested by Webb et al. (1979) may dictate such intervention (Table II). The need for ventilation is associated with a high mortality and it has been suggested that complications occur at a significantly higher rate in patients ventilated for status asthmaticus than in those being ventilated for all other causes (Scoggin et al., 1977). Dangerous complications include pneumothorax, pneumomediastinum and ventilator failure because of high inflation pressures (Scoggin et al., 1977). Ideally the decision to ventilate should be made electively before the patient is moribund.

We do not propose to provide a detailed formula for safe intubation and ventilation. However, the following important points should be stressed. A volumecycled ventilator with a variable I:E (inspiratory to expiratory time) ratio is a great advantage; respiratory frequency should be low and optimized by auscultation of the chest; expiratory time should be sufficiently long to allow all expiratory rhonchi to cease; airway pressure should be maintained below $60 \mathrm{~cm} \mathrm{H} 20$ to minimize the risk of barotrauma; hypoxaemia must be

Table II Suggested criteria for ventilation based on sequential observations

1. Evidence of deterioration in pulmonary function

Falling $\mathrm{PaO}_{2}$, rising $\mathrm{PaCO}_{2}$

Danger levels in a primary asthmatic

$-\mathrm{PaO}_{2}<5.3 \mathrm{kPa}(40 \mathrm{mmHg})$

$-\mathrm{PaCO}_{2}>6.7 \mathrm{kPa}(50 \mathrm{mmHg})$

2. Evidence of deterioration in cardiac function

Rising pulse rate $(>140$ beats/min for $>3 \mathrm{~h})$, fall in pulse volume, onset of a cardiac dysrhythmia, rising right atrial pressure.

3. General evidence of deterioration

Deterioration in level of consciousness.

Fall in urine output.

Onset of a metabolic acidosis.

4. Emergency indications for ventilation may include Irreversible respiratory depression due to drugs.

Lung collapse, acute pneumothorax or pneumomediastinum.

Onset of a cardiac dysrhythmia or evidence of heart failure.

(Each patient has to be assessed individually. It is therefore difficult to place absolute values for ventilation.)

(Adapted after Webb et al., 1979).

corrected but prolonged hypercapnia up to $12 \mathrm{kPa}$ $(90 \mathrm{mmHg}$ ) has no deleterious effect (Webb et al., 1979; Halttunen et al., 1980; Darioli \& Perret, 1984; Dales \& Munt, 1984). In addition, Webb et al. (1979) suggest that, as cardiac output may be partly sustained by hypercapnia and hypoxia (both directly and indirectly through circulating catecholamines), care must be taken not to reduce the $\mathrm{PaCO}_{2}$ by more than $1.3 \mathrm{kPa}(10 \mathrm{mmHg})$ per hour. Care must be taken to maintain the circulating volume. Sedation with diazepam is preferred because it lacks the histamine releasing effect of morphine, causes minimal depression of blood pressure and cardiac output and it has a high therapeutic:toxic dose ratio. Pancuronium is recommended for paralysis as it has no histamine releasing action and minimal cardiovascular effects 
and little ganglion blocking action (Dales \& Munt, 1984).

Intravenous bicarbonate has been advocated as an adjunct in the management of very seriously ill patients to prevent the adverse effects of acidosis on the pharmacological actions of catecholamines. Individual case reports lend some support to this view (Menitove \& Goldring, 1983). However, the strategy is not universally accepted (Webb et al., 1979). Menitove \& Goldring (1983) have recently reported the use of intravenous bicarbonate in three cases of refractory asthma requiring mechanical ventilation; the authors suggest that the strategy may be useful to maintain a physiologically normal $\mathrm{pH}$ during the acute phase when the $\mathrm{PCO}_{2}$ is increasing due to worsening bronchospasm which limits adequate ventilation, during the preparation for interventive measures such as bronchoscopy to remove mucous plugs and during extubation of the patient despite persistent hypercapnia. The potential risks of posthypercapnic metabolic alkalosis when renal bicarbonate excretion lags behind the correction of $\mathrm{PCO}_{2}$, and of possible central nervous systemic acidosis due to the difference in central nervous system permeability to carbon dioxide and bicarbonate are highlighted, and the need to monitor serum potassium, which may anyway be low due to steroids and stress and which may be aggravated by alkalosis, is underlined.

\section{References}

ALDERSON, M. \& LOY, R.M. (1977). Mortality from respiratory disease at follow up of patients with asthma. British Journal of Diseases of the Chest, 71, 198.

ARNOLD, A.G., LANE, D.J. \& ZAPATA, E. (1982). The speed of onset and severity of acute severe asthma. British Journal of Diseases of the Chest, 76, 157.

BRITISH THORACIC ASSOCIATION. (1982). Deaths from asthma in two regions of England. British Medical Journal, 285, 1251.

BRITTEN, M.G., COLLINS, J.V., BROWN, D., FAIRHURST, N.P.A. \& LAMBERT, R.A. (1976). High dose corticosteroids in severe asthma. British Medical Journal, 2, 73.

CHANG, K.C., BELL, T.D., LAUER, B.A. \& CHAI, H. (1978). Altered theophylline pharmacokinetics during acute respiratory virus illness. Lancet, i, 1132.

CLARK, T.J.H. (1983). Acute severe asthma. In Asthma. 2nd edition, Clark, T.J.H. and Godfrey S. (eds.). pp. 393. Chapman and Hall: London.

COCHRANE, G.M. (1983). Systemic steroids in asthma. In Steroids in Asthma, Clark, T.J.H., (ed.). pp. 103, ADIS Press.

COCHRANE, G.M. \& CLARK, T.J.H. (1975). A survey of asthma mortality in patients between ages 35 and 64 in the Greater London Hospital in 1971. Thorax, 30, 300.

COLLINS, J.V., HARRIS, P.W.R., CLARK, T.J.H. \& TOWNSEND, J. (1970). Intravenous corticosteroids in treatment of acute bronchial asthma. Lancet. ii, 1047.

CONWAY, S.P., GILLIES, D.R.N. \& LITTLEWOOD, J.N.

\section{Conclusion}

Despite the advent of bronchodilator drugs and corticosteroids, the death rate from asthma has been little affected. Many investigators have agreed that at least some deaths are potentially avoidable; too great a dependence on bronchodilators, underuse of corticosteroids in the acute situation and failure to recognize the severity of the attack by both the patient and the doctor have been blamed.

Although underassessment may lead to undertreatment, individual bronchodilator therapies have their own hazards. The particular risks of intravenous bolus aminophylline, especially when given with a recognized or unrecognized background of oral or rectal maintenance theophylline therapy have received much recent attention.

Mechanical ventilation carries added risks for the asthmatic but nevertheless, a small number of patients continue to require such intervention. If possible, this should be elective and with the advice of physicians or anaethestists trained in the intensive care of asthmatics.

Every asthmatic demands careful appraisal and choice of treatment. We should not have to subscribe to the conclusion of Maimonides in his medieval treatise on asthma - '. . . I have no cure to report.'

(1984). Intravenous aminophylline in acutely ill patients receiving theophylline. British Medical Journal, 288, 715.

COOKE, N.J., CROMPTON, G.K. \& GRANT, I.W.B. (1979).

Observations on the management of acute bronchial asthma. British Journal of Diseases of the Chest, 73, 157.

DALES, R.E. \& MUNT, P.W. (1984). Use of mechanical ventilation in adults with severe asthma. Canadian Medical Association Journal, 130, 391.

DARIOLI, R. \& PERRET, C. (1984). Mechanical controlled hypoventilation in status asthmaticus. American Review of Respiratory Disease, 129, 385.

EDITORIAL. (1980). Intravenous aminophylline: a cautionary note. Lancet, i, 746.

FRASER, D.M., SPEIZER, F.E., WATERS, S.D.M., DELL, R. \& MANN, N. (1971). The circumstances preceding death from asthma in young people in 1968-1969. British Journal of Diseases of the Chest, 65, 71.

GRAHAM, V.A., MILTON, A.F., KNOWLES, G.K. \& DAVIES, R.J. (1982). Routine antibiotics in hospital management of acute asthma. Lancet, i, 418.

GRANT, I.W.B. (1982). Are corticosteroids necessary in the treatment of severe acute asthma. British Journal of Diseases of the Chest, 76, 125.

HALTTUNEN, P.K., LUOMANMAKI, K., TAKKUNEN, O. \& VILJANEN, A.A. (1980). Management of severe bronchial asthma in an intensive care unit. Annals of Clinical Research, 12, 109.

HANDSLIP, P.D.J., DART, A.M. \& DAVIES, B.H. (1981). 
Intravenous salbutamol and aminophylline in asthma: a search for synergy. Thorax, 36, 741 .

HEAF, P.J.D. (1970). Deaths in asthma: a therapeutic misadventure. British Medical Bulletin, 26, 245.

HETZEL, M.R., CLARK, T.J.H. \& BRANTHWAITE, M.A. (1977). Asthma: analysis of sudden deaths and ventilatory arrest in hospital. British Medical Journal, 1, 808.

HETZEL, M.R. \& CLARK, T.J.H. (1976). Comparison of intravenous and aerosol salbutamol. British Medical Journal, 2, 919.

ISLES, A.F., MacLEOD, S.M. \& LEVISON, H. (1982). Theophylline: new thoughts about an old drug. Chest, 82, 495 .

JACKSON, R.T., BEAGLEHOLE, R., REA, H.R. \& SUTHULAND, D.C. (1982). Mortality from asthma: a new epidemic in New Zealand. British Medical Journal, 285, 771.

JONES, E.S. (1971). The intensive therapy of asthma. Proceedings of the Royal Society of Medicine, 64, 1151.

JOSEPHSON, G.W., MACKENZIE, E.J., LIETMAN, P.S. \& GIBSON, G. (1979). Emergency treatment of asthma - a comparison of two treatment regimens. Journal of the American Medical Association, 242, 639.

KAY, A.B. (1983). The immunological basis of asthma. In Steroids in Asthma. Clark, T.J.H. (ed.). pp. 46, ADIS Press.

LESLIE, D. \& COATS, P.M. (1977). Salbutamol-induced ketoacidosis. British Medical Journal, 2, 768.

LOPEZ-VEDRIERO, M.T. \& REID, L. (1983). Pathological changes in asthma. In Asthma, 2nd edition, Clark, T.J.H. \& Godfrey, S. (eds.), p. 79. Chapman and Hall: London.

LUKSZA, A.R. (1982a). A new look at adult asthma. British Journal of Diseases of the Chest, 76, 11.

LUKSZA, A.R. (1982b). Acute severe asthma treated without steroids. British Journal of Diseases of the Chest, 76, 15.

MACDONALD, J.B., SEATON, A. \& WILLIAMS, D.A. (1976). Asthma deaths in Cardiff 1963-1974: 90 deaths outside hospital. British Medical Journal, 1, 1493.

MCFADDEN, E.R.J. KISER, R. \& DE GROOT, W.J. (1973). Acute bronchial asthma. Relations between clinical and physiologic manifestations. New England Journal of Medicine, 288, 221.

MENITOVE, S.M. \& GOLDRING, R.M. (1983). Combined ventilator and bicarbonate strategy in the management of status asthmaticus. American Journal of Medicine, 74, 898.

MITENKO, P.A. \& OGILVIE, R.I. (1973). Rational intravenous doses of theophylline. New England Journal of Medicine, 289, 600 .

NICHOLSON, D.P. \& CHICK, T.W. (1973). A re-evaluation of parenteral aminophylline. American Review of Respiratory Disease, 108, 241.

NOGRADY, S.G. HARTLEY, J.P.R. \& SEATON, A. (1977). Metabolic effects of intravenous salbutamol in the course of acute, severe asthma. Thorax, 32, 559.

ORMEROD, L.P. \& STABLEFORTH, D.E. (1980). Asthma mentality in Birmingham. British Medical Journal, 1, 687.

PIAFSKY, K.M. \& OGILVIE, R.I. (1975). Disusage of theophylline in bronchial asthma. New England Journal of Medicine, 292, 1218.

PIERSON, W.E. BIERMAN, C.W. \& KELLEY, V.C. (1974). A double-blind trial of corticosteroid therapy in status asthmaticus. Paediatrics, 54, 282.

POWELL, J.W., VOSEH, S., HOPEWELL, P., CASTELLO, J., SHEINER, L.B. \& SIEGELMAN, S. (1978). Theophylline disposition in acutely ill hospitalized patients. American
Review of Respiratory Disease, 118, 229.

REBUCK, A.S. \& READ, J. (1971). Assessment and management of severe asthma. American Journal of Medicine, $51,788$.

REITBERG, D.P., BERNHARD, H. \& SCHENTAG, J.J. (1981). Alteration of theophylline pharmaco-kinetics and half-life by cimetidine in normal volunteers. Annals of Internal Medicine, 95, 582.

ROSSING, T.H., FANTA, C.H., GOLDSTEIN, D.H., SNAPPER, J.R. \& MCFADDEN, E.R. (1980). Emergency therapy of asthma: comparison of the acute effects of parenteral and inhaled sympathermimetics and infused aminophylline. American Review of Respiratory Disease, 122, 365.

RUDD, R.M. \& WEDZICHA, J. (1982). Asthma. Seminar Series. Update Publications: London.

SCOGGIN, C.H. SAHN, S.A. \& PETTY, T.L. (1977). Status asthmaticus, a nine year experience. Journal of the American Medical Association, 238, 1158.

SIEGLER, D. (1977). Reversible electrocardiographic changes in severe acute asthma. Thorax, 32, 328.

SPEIZER, F.E., DOLL, R. \& HEAF, P. (1968). Observations on recent increase in mortality from asthma. British Medical Journal, 1, 335.

STARK, J.E. (1972). Status asthmaticus. British Journal of Hospital Medicine, 8, 241.

STEWART, M.F., BARCLAY, J. \& WARBURTEN, R. (1984). Risk of giving intravenous aminophylline to acutely ill patients receiving maintenance treatment with theophylline. British Medical Journal, 288, 450.

STOLLEY, P.D. \& SCHINNAR, R. (1978). Association between asthma mortality and isoproterenol aerosols: a review. Preventive Medicine, 7, 519.

SVEDMYR, N. (1977). Asthma treatment - pharmacological principles and mechanisms of drug action. Scandinavian Journal of Respiratory Disease, 101, 13.

SVEDMYR, N. (1982). Effects of glucocorticoids on airways. European Journal of Respiratory Disease, 63, S48.

TAI, E. \& READ, J. (1967). Response of blood gas tensions to aminophylline and isoprenaline in patients with asthma. Thorax, 22, 543.

TATTERSFIELD, A.E. (1983). Autonomic bronchodilators. In Asthma, 2nd edition, Clark, T.J.G. \& Godfrey, S. (eds.) p. 301, Chapman and Hall: London.

THOMPSON, P.J. \& HAY, J.G. (1982). Dangers of compound drugs and intravenous aminophylline (letter). Lancet, ii, 1228 .

VAN DELLEN, R.G. (1979). Intravenous aminophylline. Chest, 76, 2.

WARD, M.J., FENTERN, D.H., RODERICK-SMITH, W.H. \& DAVIES, D. (1981). Ipratropium bromide in acute asthma. British Medical Journal, 282, 598.

WARD, M.J., MAcFARLANE, J.T. \& DAVIES, P. (1982). Treatment of acute severe asthma with intravenous aminophylline and nebulized ipratropium after salbutamol. Thorax, 37, 785.

WEBB, A.K., BILTON, A.H. \& HANSON, G.C. (1979). Severe bronchial asthma requiring ventilation. A review of 20 cases and advice on management. Postgraduate Medical Journal, 55, 161.

WESTERMAN, J.E., BENATAR, S.R., POTGIETER, S.D. \& FERGUSON, S.D. (1979). Identification of the high-risk asthmatic patient. American Journal of Medicine, 66, 565. WILLIAMS, S.T., WINNER, S.J. \& CLARK, T.J.H. (1981) 
Comparison of inhaled and intavenous terbutaline in acute severe asthma. Thorax, 36, 629.

WILSON, J.D., SUTHERLAND, D.C. \& THOMAS, A.C. (1981). Has the change to beta-agonists combined with oral theophylline increased cases of fatal asthma. Lancet, $\mathbf{i}$, 1235.

WOODCOCK, A.A., JOHNSON, M.A. \& GEDDES, D.M. (1983).
Theophylline prescribing serum concentrations and toxicity. Lancet, ii, 610.

ZWILLICH, C.W., SUTTON, F.D., NEFT, T.A., COHN, W.M., MATTHAY, R.A. \& WEINBERGER, M.M. (1975). Theo- ¿ phylline-induced seizures in adults. Correlation with $\subseteq$ serum concentrations. Annals of Internal Medicine, 82, 784. 